\title{
Abstracts of Papers on Animal and Physiological Psychology to be presented at the 10th Annual Meeting of the Psychonomic Society, Chase-Park Plaza Hotel, St. Louis, Missouri, November 6, 7, 8, 1969
}

Friday Morning

Discrimination Learning

9:00-9:15 B25

Compound Stimulus Presentations as an Index of Excitatory and Inhibitory Properties of Conditioned Stimuli. D. REBERG \& A. H. BLACK, McMaster University-Following multiple-CS Pavlovian conditioning procedures, excitatory or inhibitory properties of a CS may be revealed by presenting it in compound with a second CS known to be excitatory. Some applications of this technique are described, and implications on the concept of inhibition are discussed.

$$
\text { 9:15-9:30 B26 }
$$

Component Strength in Two Types of Compound Stimuli. THOMAS W. BAKER \& E. JAMES KEHOE, Lawrence University (sponsored by W. J. Brogden)-Rats received $50,150,450$, or 900 compound CS-food pairings, in either a between- or within-Ss design. Components in the compound CSs were either sequential or overlapping. Results indicate differential component strength both as a function of the number of pairings and the type of compound.

$$
\text { 9:35-9:45 B27 }
$$

Effects of Relative Distinctiveness of S+ and $\mathrm{S}-$ on Discrimination Learning. DAVID A. STEVENS, Clark University-Rats were trained to discriminate a black-white pattern and a homogeneous grey. Learning was more rapid when the pattern was $S+$ than when it was $S-$. This suggests that the results obtained from other assessments of the relative importance of $\mathrm{S}+$ and $\mathrm{S}-$ were due to nonassociative factors rather than to learned avoidance of $S-$.

$$
\text { 9:45-10:00 B28 }
$$

Can Monkeys Attend Selectively to Dimensions of Colors? FRED STOL LNITZ, Cornell University-After successive discrimination training with hue relevant and brightness irrelevant (or vice versa), followed by simultaneous discrimination training with both relevant, rhesus monkeys transferred equally (and poorly) to the hue difference alone and the brightness difference alone. The same procedure yields selective attention to spatially separable attributes, suggesting that selective fixation is important for attention.

10:05-10:10 B29

(Read by title only)

Discrimination Learning with Conditional Color Cues in the Monkey. ALLAN M.
SCHRIER, Brown University-Monkeys were trained on conditional discrimination problems, consisting of a pair of objects differing in form or, depending on the problem, in size. The conditional cue was color of the test tray for half the Ss and color of the pair of objects for the other half. The discriminative response was displacement of one of the objects. Original and reversal learning were generally better when the conditional cue was color of the objects. This agrees with previous findings that monkeys are more likely to attend to stimuli that they touch when responding than those they do not touch.

\section{BREAK}

$$
\text { 10:25-10:40 B30 }
$$

Assaying the ORE. S. E. SPERLING, UC, $R$ iverside-When the same stimulus-presentation methodsimultaneous or differential-was used in both acquisition and reversal of a visual discrimination, the likelihood of observing an ORE was negatively related to the stringency of the initial training criterion. If the stimulus-presentation method changed from acquisition to reversal, there was no evidence of an ORE.

$$
\text { 10:40-10:55 B31 }
$$

Procedural Variables in Operant Discrimination Reversal. FOGLE C. CLARK, University of North Carolina-Pigeons performed errorless or nearly errorless daily discrimination reversals after 50 sessions with a fixed order of schedules. Schedule control was weaker under two other procedures, one in which discrimination was based on an invariant sequence of procedural events, and one which maximized control by key colors.

11:00-11:05 B32

(Read by title only)

Probability Learning and Reversal by Squirrel Monkeys. F. ROBERT TREICHLER \& A. MICHAEL RICCIARDI, Kent State University-Nine squirrel monkeys were tested on the acquisition and reversal of noncorrectional object probability learning tasks at ratios of $90: 10$, $80: 20$, and $70: 30$, according to a counterbalanced sequence. All Ss displayed eventual maximizing (consistent choice of the more frequently reinforced alternative) on all tasks, although Ss on the 70:30 ratio showed significantly slower acquisition than on the other two ratios. No effects of different probability ratios were observed in reversal. Neither the order of presentation of the different ratios nor the problem sequence (1st, 2nd, 3rd) significantly influenced acquisition or reversal performances. The results were strikingly similar to those of thesus monkeys.

11:05-11:20 B33

Response Topography and Cue Information in Primate Discrimination Learning. R. T. BARTUS \& T. E. LeVERE, North Carolina State University -A discontiguous stimulus-response automated primate testing apparatus was used in a series of experiments to study the primate's in tratrial response behavior and acquisition of stimulus information during two-choice color and pattern discriminations. The major results indicated that during the initial discrimination problem, the monkeys were not only learning the appropriate instrumental response, but additionally more general $R$ patterns common to optimal discrimination learning. It was also found that the primate bases his instrumental responses on information from both the positive and negative cues even when performance is asymptotic, but that relative negativity of the incorrect cue is nonmonotonically related to performance. 11:20-11:35 B34

Stimulus Generalization as a Function of Discrimination Learning Without Error. JOSEPH E. LYONS, University of Wisconsin-Milwaukee-In a series of studies, the effec of learning a discrimination without errors was investigated. The errorless learning was produced by preventing the animal from responding at the $S-$. The measure was the slope of a generalization gradient. Where direct comparisons are possible, the results with this method replicate the findings of Terrace. Other findings with the response-prevention method indicate that the $\mathbf{S}$ - is not neutral following errorless learning.

$$
\text { 11:40-11:55 B35 }
$$

Stimulus Generaliz:tion After Discriminative or Single-Stimulus Training in the T Maze. DONALD ROBBINS, Rockefeller University, SOLOMON WEINSTOCK, Brooklyn College, \& WILLIAM K. ESTES, Rockefeller University-Rats learned a successive brightness discrimination in a $T$ maze with error trials rerun until $S$ made the correct response. A control group received 
probability learning $(\pi=.75)$ with one stimulus present and each $S$ "matched" the $\pi$-value. Discrimination $S s$ yielded generalization gradients, while the controls responded at approximately .75 throughout.

$$
\text { 12:00-12:20 B36 }
$$

Eye Orientation During Visual Discrimination Learning by Monkeys. MARLENE OSCAR-BERMAN, Harvard University, SIMON P. HEYWOOD, Oxford University, \& CHARLES G. GROSS, Harvard University--Motion pictures were taken of eyes of monkeys as they learned simultaneous pattern discriminations. Each animal looked at one side more than at the other, and, during acquisition, looked more at the correct than at the incorrect stimulus. Preferred position of gaze, preferred eye, and preferred hand were not invariably ipsilateral.

\section{Friday Afternoon \\ Animal Learning I}

\section{$1: 15-1: 30 \mathrm{~B} 37$}

Effects of Patterns of Goalbox Placements on the Subsequent Acquisition of Instrumental-Response Patterning. J. J. FRANCHINA, Virginia Polytechnic Institute, D. L. SPARLING, \& R. CHLIPALA, De Paul UniversityA]ternation of reward and nonreward during goalbox or neutral-box placements faciljtated subsequent instrumental response patterning over that for placements with $100 \%$ or $0 \%$ reward or random reward and nonreward. Random procedures facilitated response patterning over $100 \%$ or $0 \%$ procedures for goalbox but not for neutral-box placements.

$$
\text { 1:30-1:40 B38 }
$$

Rats Prefer Brief to Prolonged Warnings for Brain Stimulation. VINCENT $M$. LOLORDO \& MICHAEL B. CANTOR, University of North Carolina at Chapel Hill-Rats received reinforcing brain stimulation on a variable interval schedule on both sides of a shuttlebox. The ESB was preceded by a brief $(0.5$-sec) warning signal when the rat was on one side, but by a long $(10-\mathrm{sec}$ or $30-\mathrm{sec})$ one when he was on the other. There was a strong preference for the brief warning signal.

$$
\text { 1:45-1:55 B39 }
$$

Brief Stimuli in Second-Order FR (FI) Schedules. DONALD F. McCAUSLAND \& JOHN C. BIRKIMER, University of Louisville-Four albino rats were reinforced for bar-pressing on second-order FR 3 (FI $1 \mathrm{~min}$ ) schedules. A brief exteroceptive stimulus after each FI component increased rates preceding the stimulus and reduced rates following it, suggesting both conditioned reinforcing and conditioned suppressing effects. The conditioned reinforcing effects, however, did not appear in intervals immediately following primary reinforcement.

$$
\text { 1:55-2:05 B40 }
$$

Habituation to Environmental and Specific Auditory Stimuli in the Rat. ARTHUR R. ZEINER \& HARMAN V.S. PEEKE, UC San Francisco Medical Center-Rats were trained to drink from a spout in a sound-attenuated chamber. Half of the animals were trained to lick for 14 days. The second half of the Ss were presented with the drinking spout only for Days 8-14. In a second phase, half of each group was presented with rats' cries while drinking; the second half received pure tones. Suppression of drinking, frequency of wall climbing, grooming, and defecation were monitored. It was found that: (1) habituation to the chamber was the primary variable influencing acquisition rate of the licking response and (2) suppression of drinking to rat cries was more resistant to habituation than a pure tone.

$$
\text { 2:10-2:25 B4I }
$$

The Effects of Cue Placement Within Delay Interval on Acquisition and Extinction Performance. TOM N. TOMBAUGH, Carleton University-The relationship between delayed reinforcement and cues was investigated by placing a light cue at different temporal locations within the delay interval. In acquisition, a cue placed at the beginning $(\mathrm{CN})$, end $(\mathrm{NC})$, or throughout the duration of the interval (CC). In extinction, half of each group received the same cue as experienced in acquisition and half did not receive any cue. Two other groups (0-sec delay and 7.5-sec delayY were employed that did not receive any cue in acquisition or extinction. The results demonstrated the following: (1) Delayed reinforcement without cue resulted in inferior performance in both acquisition and extinction, (2) the performance of the groups that received the cue in extinction was superior to those that did not receive the cue, (3) the $\mathrm{CC}$ condition produced the best performance in acquisition and extinction followed by the $\mathrm{NC}$ and $\mathrm{CN}$ conditions, respectively.

$$
2: 25-2: 40 \text { B42 }
$$

Reinforcement Density in Multistimulus Conditioned Suppression. BARRY S. MARKMAN, Emory University (sponsored by Eugene Winograd)-Using a conditioned suppression procedure, stimulus elements were trained using different percentages of reinforcement prior to the introduction of reinforced trials with a compound stimulus, composed of the trained $\mathrm{CS}$ and a stimulus of another modality. The individual elements of the compound were then tested in extinction. The results indicate the greater the increase in percentage of reinforcement between the two training phases, the greater the probability of the new stimulus in the compound becoming a $\mathrm{CS}$. The procedure was then replicated with manipulations in CS-US interval.

2:45-2:50 B43

(Read by title only)

Errorless Learning in Split-Brain Monkeys. J.D. JOHNSON \& M. S. GAZZANIGA, New York University-Three experienced split-brain Ss were trained a visual pattern discrimination in one eye-hemisphere. After several hundred trials of overlearning, the opposite, untrained eye-hemisphere was allowed to observe 40 perfect trials. Subsequently, 10 nonreinforced probe trials were delivered exclusively to the untrained hemisphere. Two Ss performed perfectly, while another required 40 additional observation trials before a perfect score was realized. The results are consistent with the view that errors during acquisition training need not be a necessary condition for visual discrimination learning.

\section{BREAK}

\section{3:05-3:20 B44}

Inhibitory Gradients Obtained with Nondifferential Reinforcement During Generalization Testing. SERENA $S$. BESLEY \& ELIOT HEARST, University of Missouri, Columbia-After extinction to one line-tilt, pigeons yielded generalization gradients during continued daily tests with nondifferential reinforcement at all line-tilts (instead of the conventional testing-in-extinction procedure). This method produced very clear and reliable inhibitory gradients around $\mathrm{S}-$. Over 12 sessions of continued nondifferential reinforcement, the original gradient minimum frequently became the maximum.

$$
\text { 3:20-3:35 B45 }
$$

Spontaneous Recovery and Generalization of Extinction. HOWARD ORENSTEIN, DONALD A. SCHUMSKY, THOMAS ROTH, \& ROBERT BRUNNER, University of Cincinnati-Eight groups of seven rats each were run in a straight alley to de termine the role spontaneous recovery interval plays in generalization of extinction. Groups were trained on a CS of $20 \mathrm{~cm}^{2}$, extinguished on 20 or $79 \mathrm{~cm}^{2}$, and reextinguished after 5 or $185 \mathrm{~min}$ on either 20 or $79 \mathrm{~cm}^{2}$. Generalization of excitation and extinction, as well as recovery, were a function of test stimulus used and recovery interval. Discussion of results considered time as a possible dimension for stimulus generalization.

$$
\text { 3:40-3:55 B46 }
$$

A Negative Contrast Effect Following Reinforcement Reduction in Escape Conditioning. PAUL J. WOODS, Hollins College-In a cold-water-escape situation, rats were trained for five 25-trial sessions 
with a large temperature increment and then shifted to a small one. Performance following the shift was significantly inferior to a small-increment control group-a finding analogous to the "Crespi depression effect" in appetitive conditioning.

$$
\text { 3:55-4:10 B47 }
$$

Specific and Nonspecific Components of Retention in Young and Adult Rats. MICHAEL ROHRBAUGH \& DAVID C. RICCIO, Kent State University-Young and adult rats were compared in retention of a specific fear response, as well as in retention of nonspecific consequences (interference with subsequent escape performance) of the original fear-learning experience. Retention loss in both cases decreased with age.

$$
\text { 4:15-4:30 B48 }
$$

Differential Conditioning to Visual and Gustatory Cues in Quail and Rat: Illness-Induced Aversions. HARDY C. WILCOXON, WILLIAM B. DRAGOIN, \& PAUL A. KRAL, George Peabody College (sponsored by Gilbert W. Meier)-Forty Bob White quail and 40 albino rats were compared as to the readiness with which conditioned aversions could be established to the ingestion of distinctively flavored and distinctively colored water. After establishment of baseline drinking of plain water (10 min per day for 1 week), subgroups of each species received an initial 10 -min exposure to water that was either blue or sour, or both blue and sour. One-half hour after removal of the distinctive fluid, all Ss were injected intraperitoneally with an illness-inducing drug (cyclophosphamide). Subsequent drinking tests with the distinctive fluids showed that while taste was the only effective avoidance cue for the rats, the visual cue was more salient than taste for the quail.

$$
\text { 4:35-4:40 B49 }
$$

(Read by title only)

Domestication and Avoidance Learning in Norway Rats. ROBERT BOICE \& JANET G. WITTER, University of Missouri, Columbia-Rattus norvegicus in three stages of laboratorization were outperformed by domesticated rats in a shuttlebox task. Avoidances in wild $F_{1}$ and in wild-caught laboratory-habituated rats were equivalent and exceeded avoidances in new captives. Behaviors in the undomesticated rats were comparatively stereotyped and inflexible. Since wild rats appear to occupy niches where learning is atypical in adulthood, it is suggested that only in domestication can rats acquire both the genotype and ecotype to permit a continual emphasis on learning. Conclusion: Domesticated rats are more appropriate for generalization to domesticated humans.

$$
\text { 4:40-4:45 B50 }
$$

(Read by title only)

Extinction of the Excretory Alkali Metal Response (EAMR) in a Reptile. IRWIN M.
SPIGEL \& ALEX RAMSAY, University of Toronto-Some parameters in the extinction of the stress-induced potentiation of $\mathrm{Na}^{+}$and $\mathrm{K}^{+}$excretion in turtles were examined. A pattern typical of conditioned response decrement was obtained with termination of shock: and the sensitivity of EAMR extinction to differential antecedent shock administration was demonstrated. (Rate of excretory cation decrement differed for turtles administered 3 and $6 \mathrm{~h}$ of preshock experience). It was also found that the increment in urinary $\mathrm{Na}^{+}$and $\mathrm{K}^{+}$following shock administration in a consistent daily pattern was much more resistant to extinction than that observed in randomly shocked Ss. This finding is at variance with results so far obtained with rat and man.

Saturday Morning, Animal Learning II

$$
\text { 9:00-9:10 B51 }
$$

Partial and Varied Reinforcement Effects with Sucrose Rewards. ALEXANDER J. ROSEN \& P. E. FREEDMAN, University of Illinois-Rats reinforced with drinkometer-administered sucrose for a running response in a straight alley exhibited increased resistance to extinction following partial reward training (PRF) but not following varied reward training (VRF). This difference was interpreted as being a function of the competing responses emitted by PRF Ss on nonreinforced acquisition trials that were precluded in the VRF Ss by removal of S immediately upon withdrawal of the drinking tube. 9:10-9:25 B52

Interactive Effects of Reward Magnitude and Intertrial Interval on Extinction Behavior. J. M. BLOOM, Texas Research Institute, \& JAMES MILSTEAD, University of Houston-Rats were trained in the straight runway according to a factorial design, combining two levels of reward magnitude, two levels of acquisition intertrial interval, and two levels of extinction intertrial interval. Small reward. produced greater resistance to extinction than large reward only if combined with long acquisition intertrial interval. 9:30-9:40 B53

A Test of Amsel's Multiple-Pellet Reward Hypothesis. AMADO M. PADILLA, SUNY at Potsdam, \& DOUGLAS SPANIER, Stanislaus State College (sponsored by Frank A. Logan)-Forty rats were given CRF acquisition training in a straight nuway. Trials, goalbox placements, and multiple pellet rewards were varied orthogonally among four groups of Ss. Following acquisition, Ss were extinguished. The results, as measured by resistance to extinction, support, in part, the Amsel, Hug, and Surridge (1968) hypothesis of the role of multiple-pellet rewards. c). 40 0.55 1354

Magnitude of Reinferment lifects After Extended Traming. GARVIN MCCAIN. University of Texils al Arlinglon Results from a series of studies indicalte llat following extended training. Hsing ciller consistent or random partial reinforement, Ss given small reward $(45 \mathrm{mg})$ run as fast as Ss given large reward (500 mg). The usual extinction effects were obtained at lower levels of training, but with extended traming there were no differences. Alternative explanations are considered.

Saturday Morning. Punishment

$$
\text { 10:15-10:30 B55 }
$$

Conflict and Reversal Learning. EILEEN B. KARSH, Temple University-Rats, given a choice between a rewarded alternative and a conflict alternative, developed position fixations when the position of the alternatives was reversed. In contrast, all animals given one rewarded alternative and another nonrewarded (or punished and nonrewarded) alternative learned to choose the rewarded side during successive reversals.

$$
\text { 10:30-10:45 B56 }
$$

One-Trial Conditioned Suppression Increases with Time. JAMESC. BROPHY \& KEITH N. CLAYTON, Vanderbilt University-After a single pairing of a tone and electric shock, thirsty rats were tested for conditioned suppression with the tone presented while drinking. Rats tested immediately after the conditioning trial showed less suppression than those tested 24 or $72 \mathrm{~h}$ later, a result opposite of forgetting. 10:50-11:05 B57

Discriminative Punishment and the Conditioned Emotional Response. RUSSELL M. CHURCH, CAROL $L$. WOOTEN, \& T. JAMES MATTHEWS, Brown University-In discriminative punishment, the magnitude of suppression was determined by the stimulus and response, but in CER it was determined by the stimulus alone. In a discriminative punishment procedure that did not involve an increase in the frequency of shocks during a stimulus, a nonassociative effect of contingency was identified.

$$
\text { 11:05-11:20 B58 }
$$

Recovery from Coningent and Noncontingent Shock. ERLING E. BOE, University of Pennsylvania-Using the procedures of Hunt and Brady (1955), signalized punishment Ss recovered more rapidly than CER Ss, just as they found. With number of shocks controlled, however, no differences in recovery appeared. These findings were subsequently replicated under somewhat different conditions. 
11:25-11:40 B59

Interspersed Punishment During Acquisilion of a Shock-Escape Response ind its Effect upon Resistance (o) lixtinction. R. CHRIS MARTIN, PHILIP D. GOLDSTEIN, \& BARBARA L. DEEMER, University of Missouri at Kansas City.Groups of rats were given shock-escape training in a straight runway. One group of Ss had a number of punished trials interspersed among further acquisition trials. Resistance to extinction of the punished Ss was equal to that of nonpunished Ss. Results are discussed in terms of characteristics of aversive motivation.

\section{Thursday Morning, Brain Function}

$$
\text { 9:00-9:10 C1 }
$$

Comparison of Early and Late Blinding of Rats on the REM Moiety. ALBERT M. ANCH \& DONALD I. TEPAS, St. Louis University-The effects of early and late blinding on the amount of REM activity for two groups of rats was determined and the results compared to the amount of ambulatory activity in an open-field situation. The results showed a significantly greater amount of REM for the early blinded group while no major difference between the two groups on ambulatory activity.

$$
\text { 9:10-9:20 C2 }
$$

Running Controlled with Lateral Hypothalamic Injection of Cholinergic Drugs. DOUGLAS E. SMITH, Princeton University (sponsored by Leon J. Kamin)-Crystalline carbachol or neostigmine injected into the lateral hypothalamus of rats significantly increased wheel running. Carbachol, but not neostigmine, also increased food and water intake. Conversely, atropine injected into the same site significantly reduced running and feeding, but had no effect on water intake. The results indicate that the lateral hypothalamus contains cholinoceptive neurons that control running.

$$
\text { 9:25-9:45 C3 }
$$

Heart Rate Conditioning to Central Stimulation. NEIL SCHNEIDERMAN, University of Miami-Heart rate, blood pressure, and plethysmographic discriminations we re classically conditioned in rabbits using subcortical electrical stimulation as the CSs and US. Adrenergic and cholinergic bases of septal and hypothalamic elicited URs were examined by means of pharmacological blockades. Some US locations were assessed instrumentally across an appetitiveness-aversiveness dimension.

$$
\text { 9:45-9:55 C4 }
$$

Increases in the Cat's Sensitivity to Electrical Brain Stimulation. FREYA
JARVIS \& IRANCIS COLAVITA, University of Pittshurgh (sponsored by Robert A. Patton) A psychophysical precedure was employed le determine the $75 \%$ detection threshold for stimulation in the area of the inferior colliculus in cats. Within 10 successive test days, the detection threshold dropped by an average of $72 \%$. The data suggest that the observed threshold shift was due to a neural change. 10:00-10:15 C5

Incubation of One-Trial Discriminated Avoidance in Hippocampectomized and Amygdalectomized Rats. HUGH A. MARQUIS, K. YOUNG, \& MILTON D. SUBOSKJ, Queen's University-Response latency incubates, i.e., changes as a function of time following conditioning, in hippocampal-lesioned Ss, whereas response choice does not. Opposite effects, i.e., response choice but not response latency changes, occur in amygdala-lesioned Ss. Hypotheses of lesion-produced memory deficits do not account for these results.

$$
\text { 10:15-10:30 C6 }
$$

Is Hippocampal Electrical Activity Altered by Training? C. H. VANDERWOLF \& I. WISHAW, University of Western Ontarjo-Rats were trained in bar-pressing, shock avoidance, and running in a motor-driven wheel. Hippocampal slow activity was correlated with movement and changed with training only when the movement pattern also changed. Hippocampal activity is related to movement and is not a reflection of the learning process in itself.

\section{BREAK}

$$
\text { 10:50-11:05 C7 }
$$

Reaction Time in Pyramidotomized Monkeys. CHARLES H. BECK, University of Pennsylvania (sponsored by Eliot Stellar)-Four rhesus monkeys made normal postoperative reaction times following unilateral section of the medullary pyramids. Further testing indicated that a reaction time deficit in the forelimb contralateral to the lesion appeared when the monkey was required to make rapid choices between competing responses or when the response cues were self-generated. 11:05-11:20 C8

Intersensorily Evoked Brain Potentials in Man. T. SHIPLEY, University of Miami Medical School, S. RAWLINGS, University of Miami, M. POPP, \& C. WIER, University of Miami Medical School-Brain potentials evoked by separate and simultaneous visual, auditory, and tactile stimuli are presented, as obtained from retarded, dyslexic, and normal children. These are then compared to responses obtained from normal adults. Finally, new methods are presented for objectively gauging intersensory facilitation and inhibition, within and between these modalities.

$$
\text { 11:25-11:45 C9 }
$$

Behavioral Temperature Regulation in the Squirrel Monkey. ELEANOR R. ADAIR, John B. Pierce Foundation Laboratory $-\mathbf{A}$ color film and slides demonstrate the existence of multiple thermoregulatory sites providing signals for behavioral thermoregulation; one is located in the hypothalamus and at least one other is located elsewhere in the body. When local hypothalamic temperature is artificially manipulated, signals from the other site(s) may affect thermoregulatory behavior.

$$
\text { 11:45-12:00 C10 }
$$

Avoidance Learning in Rats with an Inborn; Error of Metabolism. RICHARD E. BUTCHER, JOHN TRINDER, Children's Hospital Research Foundation Institute for Development Research, Cincinnati, THOMAS G. ROTH, ROBERT L. BRUNNER, \& RONALD R. ROSSI, University of Cincinnati (sponsored by Marvin Schwartz)Gunn rats are a strain that inherits an enzymatic defect leading to brain damage directly comparable to that occurring in children with cerebral palsy from $\mathrm{Rh}$ incompatibility. In the present study, animals were tested in one- and two-way active-avoidance tasks. Affected Gunn rats were severely retarded at both tasks when compared with unaffected littermate controls and Wistar controls not of the Gunn substrain. Evidence indicates that the avoidance deficits cannot be attributed to locomotor impairment, although sensory deficits cannot be ruled out.

\section{Thursday Afternoon}

\section{Physiological Psychology (General)}

$$
\text { 1:00-1:15 C11 }
$$

Visual Evoked Cortical Responses to Patterned Stimuli in the Human Infant. M. RUSSELL HARTER \& CONNIE SUITT, University of North Carolina at Greensboro (sponsored by Kendon Smith)-A new technique was used to investigate the development of the visual system and pattern vision during infancy. Visual evoked cortical potentials were obtained from a human infant ( 21 to 155 days old) in response to checkerboard patterned light flashes (individual checks subtending from 20 to $133 \mathrm{~min}$ of $\mathrm{arc}$ ). The evoked responses indicated that the 21-day-old infant discriminated patterned flashes, containing checks as small as $\mathbf{2 0}$ min of arc, from blank flashes. As the infant matured, successively smaller check sizes evoked the greatest amplitude responses.

$$
\text { 1:15-1:30 C12 }
$$

Visually Evoked Cortical Responses: Attention, Uncertainty, and Stimulus 
Complexity. ROBERT G. EASON, M. RUSSELL HARTER, \& PATRICIA JOHNSON, University of North Carlina at Greensboro-Visual evoked cortical responses were obtained to the onset and offset of checkerboard and "blank" patterns randomly projected to the same retinal area. Attention was varied by measuring Ss' reaction times (RTs) to five events: onset of the checkerboard or blank pattern (choice RT stimuli); onset of the stimuli, regardless of pattern (simple RT stimuli); offset of the checkerboard or blank pattern simple RT stimuli). The results indicated that attention, uncertainty, pattern, and stimulus onset vs offset influenced evoked response amplitude.

$$
\text { 1:35-1:45 C13 }
$$

A Cardiac Deceleration Phenomenon in the Human Newborn. LEWIS P. LIPSITT \& CAROL N. JACKLIN, Brown University-Cardiac deceleration to stimulation is characteristic of older infants but is rarely found in newborns. Data will show that reliable deceleration can be obtained using non-noxious (pleasant?) odorants. Cardiac deceleration constitutes a reliable individual difference variable; $r$ greater than 60 obtained between first and second testing days.

$$
\text { 1:45-2:00 C14 }
$$

Interanimal Memory Transfer: A New Interpretation. DONALD G. STEIN, BONNIE FRANK, \& JEFF ROSEN, Clark University-Three groups of mice (donors) received the following conditions: (a) run from light to dark area and receive shock upon entering the latter; (b) same situation but without shock; (c) subjected to intense stress in completely different situation. Naive recipient groups were then injected (IP) with either brain or liver homogenates and placed in the straight alley $6 \mathrm{~h}$ after injection. Ss receiving brain and liver homogenates from shocked donors had higher latencies than no-shock controls. Highest latencies were obtained from Ss receiving extracts from the external stress donors. This was true for both liver and brain groups. A hypothesis more parsimonious than that of memory transfer will be discussed.

$$
\text { 2:05-2:25 C15 }
$$

Escape/Avoidance and Punishment Behavior in the Fetally Irradiated Rat. JOAN C. MARTIN, Duke Medical Center-Osborne-Mendal rats irradiated on one of Days 17, 19, or 21 of gestation with $200 \mathrm{R}$ exhibited significantly more bar-press escape/avoidance responses as a function of increase in shock intensity than did sham-irradiated controls. In a two-bar punishment/appetitive paradigm, irradiated Ss initiated significantly fewer shock-on periods and tended to discriminate contingencies less well, thus making a greater number of inappropriate responses as intensity was increased.

$$
\text { 2:25-2:40 C } 16
$$

Acquisition of a Free-Operant Avoidance Schedule by Normal and Protein-Malnourished Rats. PAUL $H$. HAMLIN, Rutgers University (sponsored by George H. Collier)-On an operant-avoidance schedule, protein-malnourished rats initially responded more and took fewer shocks than normals. As avoidance improved, malnourished rats held the bar longer, responded less, and had different IRT distributions. Thus, learning differences attributed to protein-malnourished rats may be confounded by their response to stressful stimuli.

$$
\text { 2:45-2:50 C17 }
$$

(Read by title only)

Mechanisms Involved in Activity-Related Self-Starvation. GEORGE F. STRUTT \& CHARLES N. STEWART, Franklin \& Marshall College-Self-starvation by rats given access to activity wheels during adaptation to a 23-h food-deprivation schedule has been reported. Examination of blood glucose levels in self-starving and home-cage controls indicated that the former are hypo-rather than hyperglycemic in comparison with controls, thus ruling out activity-induced hyperglycemia as an explanation for self-starvation. In a second experiment, stimulation of gluconeogenesis through administration of $A C T H$ produced adrenal hypertrophy but no effect on the self-starvation phenomenon.

\section{BREAK}

\section{3:05-3:20 C 19}

Conflict Duration and Incidence of Stomach Ulcers in the Rat. WILLIAM P. PARE, VA Hospital, Perry Point, Md.-Long Evans rats, exposed to continuous conflict for 10 days, showed a higher incidence of ulcers as compared to rats exposed for either 4 or 21 days. Body weight and ulcer incidence data pointed to an adaptation pattern, suggesting that if the $S$ survived beyond 10 days, the gastrointestinal pathology diminished.

$$
3: 20-3: 45 \text { C20 }
$$

The Effect of Intrahypothalamic Injection of Endogenous Amines on Behavioral and Physiological Thermoregulation in the Rat. ALEXANDER L. BECKMAN, Institute of Neurological Sciences, University of Pennsylvania (sponsored by Eliot Stellar)-Acetylcholine ( $\mathrm{ACh}$ ) and norepinephrine (NE) were injected in to the preoptic area and anterior hypothalamus. ACh produced monotonic, dose-related decreases in rate of responding for peripheral radiant heat and hypothalamic temperature (Thy). NE produced monotonic, dose-related increases in rate of responding and Thy. These observations suggest that hypothalamic neurones responsible for the coordinated activation of physiological and behavioral heat-loss mechanisms are cholinoceptive, whereas those activating heat-production responses are adrenoceptive.

$$
\text { 3:45-4:00 C21 }
$$

Sex Differences in Hyperphagia and Body Weight Gains after Hypothalamic Destruction in Rats and Mice. DEVENDRA SINGH, Iniversity of Texas at Austin-Female rats with electroly tic lesions in ventromedial hypothalamic area and female mice injected with goldthioglucose exhibit a greater degree of hyperphagia and gain more body weight than similarly treated, age-matched male $S$ s.

$$
\text { 4:00-4:15 C22 }
$$

Effect of Septal Lesions on Detection of and Unconditional Response to Shock. JOELF. LUBAR, University of Tennessee-Septal and control rats are similar in their shock detection thresholds as evidenced by gross bodily movement to shocks of various intensities. Furthermore, septals and controls do not differ in their habituation to repeated shock presentations. However, septals are more active in the intershock interval.

$$
\text { 4:20-4:30 C23 }
$$

Interpolation of Electroconvulsive Shock During CS-UCS Interval as an Impediment to the Conditioning of Taste Aversions. PAUL A. KRAL, George Peabody College (sponsored by Laird W. Heal)-Theory asserts that close temporal contiguity between stimulus events is essential for association. Apparently, short-term electrical reverberatory activity representing the $C S$ must be active at the time of UCS presentation. Yet, recent evidence indicates conditioning of gustatory aversions occurs despite CS(taste)-UCS(iliness) intervals of several hours. The present study paired sour water (CS) and poison-induced illness (US) with an interstimulus delay of $30 \mathrm{~min}$. ECS disrupted conditioning without causing retrograde amnesia for the $\mathrm{CS}$, supporting the position that the retention of the CS during the CS-US interval was trace or reverberatory in nature.

$$
4: 30-4: 45 \quad C 24
$$

The Effects of Relatively Long Training-to-Test Intervals on a Temporally Graded ECS.Produced Response Decrement in Rats. RICHARD A. HUG HES, ROBERT J. BARRETT, OAKLEY S. RAY, VA Hospital, Pittsburgh-Electroconvulsive shock was given to rats 10,120 , or $3,600 \mathrm{sec}$ after passive avoidance training. Separate groups were tested 1, 24, or 42 days later. A temporally graded response decrement was observed on the 1-day test but not on the 24 or 42-day test. 


\section{4:50 -4:55 C25}

(Read by title only)

Retrograde Amnesia for a Passive-Avoidance Task Following Anterior and Posterior Routes of Head-Shock Administration. RICHARD A. KING, University of North Carolina, Chapel Hill, \& WILLIAM FARRELL, St anford University-SpragueDawley rats were trained in one-trial passive avoidance and then tested for memory of the response after posttrial shock to the head. Head-shock was administered through screws implanted in the skull. Posterior head-shock was given be tween screws placed on either side of the midline and $4 \mathrm{~mm}$ behind the lambda suture; anterior head-shock was administered between screws on either side of the midline and $4 \mathrm{~mm}$ anterior to the bregma suture. Several groups were run as controls and several groups were run with different current values of head-shock at both posterior and anterior locations. Results: Retrograde amnesia was obtained from all Ss with anterior currents of 17 and $10 \mathrm{~mA}$. Pusterior head currents at these values produce very little retrograde amnesia. We are continuing the differentiation of posterior and anterior retrograde amnesia effects with lower current values; we also wish to discuss this finding in terms of its implications for other consolidation studies.

\section{Friday Morning, Brain Stimulation}

$$
\text { 9:00-9:20 C26 }
$$

Modification of Goldfish Visually-Evoked Potentials by Hypothalamic Stimulation. DAVID INGLE, Harvard Medical School-Averaged flash-evoked potentials recorded within the goldfish optic tectum were strongly modified during anodal polarization of the ipsilateral hypothalamus. Aftereffects in waveforms were noted in the opposite direction of the initial change. The bimodal effect may be related to dual mechanisms controlling autonomic and behavioral manifestations of hypothalamic activity.

$$
\text { 9:20-9:30 C27 }
$$

Taste and Hypothalamic Reinforcement. BARTLEY G. HOEBEL, Princeton University-Lateral hypothalamic self-stimulation and stimulation escape were measured in rats with indwelling tubes for dripping solutions on the tongue. The taste of sucrose, but not water, increased self-stimulation and at the same time decreased escape. Quinine had mixed effects on self-stimulation, but always increased escape. Thus, in some respects, hypothalamic reinforcement reflects taste preferences.

$$
\text { 9:35-9:50 C28 }
$$

Elicitation and Blockade of Thirst Induced
byCentral Application of Eserine in the Rat. ROBERT A. LEVITT \& RICHARD $P$ BOLEY, Southern Illinois University-The limbic system-diencephalic sites from which drinking could be elicited by application of carbachol were compared to those from which drinking could be elicited by eserine. In a second study, drinking induced by central application of eserine was inhibited by injecting atropine into other positive drinking sites.

9:50-10:05 C29

Reversal of Adrenergic Satiety for Food by Alpha-Adrenergic Blocking Agents. D. L MARGULES, Wyeth Labs-Direct application of norepinephrine (NE) to the brain suppresses milk intake; conversely, such application of phentolamine, an alpha-adrenergic blocker, causes overeating. Systemically (IP) administered NE also suppresses milk intake. In the present study, IP administration of chlorpromazine, an alpha-adrenergic blocker which penetrates the blood-brain barrier, strongly reversed the suppressant effect of NE (IP). Phentolamine, which poorly penetrates this barrier, showed weaker reversals. Propranolol, a beta adrenergic blocker, showed no reversals. Thus, results with both systemically and directly administered drugs support the theory that alpha-adrenergic receptors in the brain mediate the suppression of feeding associated with satiety.

\section{0:10-10:25 C30}

Circadian Rhythm of Brain Self-Stimulation Behavior. MICHAEL TERMAN \& JIUAN TERMAN, Northeastern University-Under constant conditions of light, sound, temperature, and humidity, rats exhibited circadian rhythmicity in bar-pressing with hypothalamic and septal brain-stimulation reinforcement. Variations in reinforcer magnitude affected absolute levels of operant response emission, but not the phase of the circadian pattern. In long sessions, the rhythm exhibited the classic gradual phase shift.

\section{Friday Morning, Brain Lesions I}

$$
\text { 10:45-11:05 C31 }
$$

Is the Delayed Response Deficit in Frontal Monkeys Apparatus-Specific? IVAN DIVAC, Pennsylvania State University (sponsored by J. M. Warren)-Monkeys learned delayed response in a new apparatus more slowly than cats tested in this situation. Dorsolateral frontal ablation abolished delayed response capability in the monkeys. The prefrontal cortex seems to be more critical for delayed response in monkeys than cats, in this situation as well as in the WGTA.
11:05-11:15 C32

Role of Somatosensory Cortex in Temperature Discrimination in the Rat. STANLEY FINGER, STEPHEN SCHEFF, IRA WARSHAW, KAREN COHEN, \& JOHN MORRISON, Washington University-Rats with histologically confirmed lesions of one or both somatosensory cortical areas, occipital cortex, or sham operations were tested for retention of $29^{\circ}$ vs $39^{\circ} \mathrm{C}$ and $29^{\circ}$ vs $34^{\circ} \mathrm{C}$ temperature discriminations, and for acquisition of a $29^{\circ}$ vs $31^{\circ} \mathrm{C}$ habit. Statistical analyses failed to reveal any group differences. Results suggest that thermal habits are mediated by a diffuse and redundant cortical system, and/or that significant sensory appreciation may take place subcortically.

$$
\text { 11:20-11:35 C33 }
$$

Deficits in Visual Pattern Discrimination After Auditory Cortical Lesions in Cats. FRANCIS B. COLAVITA, University of Pittsburgh-Cats were trained in a double grill box to discriminate between two temporal patterns of blinking lights. Following acquisition of the discrimination, bilateral ablation of different parts of anditory cortex was performed. Postoperative retraining indicated that relearning was only possible for animals in which the insular-temporal areas had been spared.

$$
\text { 11:35-11:45 C34 }
$$

Corpus Callosum Section and Selective Attention to One Ear. JOHN H. KAAS, University of Wisconsin, \& I.T. DIAMOND, Duke University-Cats were trained to respond to a change in frequency presented to one ear and to ignore the same change in the other ear. The discrimination was lost after ablation of auditory cortex contralateral to the attentive ear. Section of the corpus callosum before training prevented the loss.

$$
\text { 11:50-12:00 C35 }
$$

Caudate Nucleus Lesions and Avoidance Conditioning in Squirrel Monkeys. ROGER K. THOMAS, JR., University of Georgia-Squirrel monkeys with lesions of the caudate nucleus reached criterion significantly sooner in simple avoidance conditioning than nonoperated monkeys, but the caudates took significantly more trials to criterion in discrimination training. Caudates responded significantly more to the CS+ in both conditions and to the CSin discrimination.

\section{Friday Afternoon, Brain Lesions II}

$$
1: 15-1: 25 \text { C36 }
$$

EEG Correlates of the Rage Syndrome in Rats. BLAIR H. TURNER, University of Pennsylvania Medical School (sponsored by 
Eliot Stellar)-EEG abnormalities were obtained from cortical dural and depth electrodes in rats following lesions of the septal area. A high amplitude $(200-\mu \mathrm{V})$ burst of $4-5 / \mathrm{sec}$ waves (sigma rhythm) was elicited on presentation of a novel or threatening stimulus. A number of abnormalities of the electrical signs of sleep were also observed. 1:25-1:40 C37

Path Preferences in a Dashiell Maze Following Septal and Hippocampal Lesions. PAUL ELLEN \& OWEN BATE, Georgia State College-Rats with limbic lesions prefer peripheral as opposed to center paths in a Dashiell maze when the center paths are painted white and the peripheral paths black. Reversing the path markings causes the lesioned animals to choose the central paths. Results are discussed in terms of factors controlling the maze habit.

$$
\text { 1:45-2:00 C38 }
$$

Hippocampal Lesions Impair Trace Conditioning. STUART R. HALL \& EARL C. HAGSTROM, University of New Hampshire-The acquisition of a discrete-trial lever-press shock avoidance to an auditory stimulus was studied in rats with hippocampal lesions and controls under conditions of delayed and trace conditioning (CS-US interval $5 \mathrm{sec}$ ). Ss with dorsal hippocampal lesions failed to acquire the trace conditioning task but succeeded on the delayed task. Ventral hippocampal lesions and sham operations were without effect. The deficit, involving failure to respond rather than response perseveration, is discussed in terms of the orienting response and short-term memory.

$$
\text { 2:00-2:10 C39 }
$$

Hippocampal Lesions and Discrete Trial DRL Performance in a Runway. THOMAS S. BROWN, Michael Reese Hospital, Chicago, and FRANK V. MARSICO, De Paul University-Hippocampal lesioned rats were compared with cortically lesioned and unoperated controls in a runway discrete-trial DRL test for 60 days. Traversing the runway in $5 \mathrm{sec}$ or more resulted in food reward, a response of less than 5 sec resulted in no reward and a $30-\mathrm{sec}$ goalbox confinement. Rats with hippocampal lesions were severely impaired on this test.

\section{BREAK}

\section{2:30-2:45 C40}

Facilitation of Single Alternation Go/No-Go Performance Following Hippocampectomy. DON W. WALKER, LARRY W. MEANS, University of Florida Medical Center, \& ROBERT L. ISAACSON, University of Florida-Rats with hippocampal ablations, cortical control lesions, and normals were trained on a go/no-go single-alternation task in a bar-press situation.
Hippocampectomized Ss were more efficient than control Ss at withholding responses on nonreinforced no-go trials and at responding on the food reinforced go trials as measured by latency to the first response and number of responses on each trial.

$$
\text { 2:45-3:00 C41 }
$$

Effects of Midbrain Reticular Lesions upon the Orienting Response. EDRIC $W$. VREDENBURG III \& RAYMOND P. KESNER, University of Utah-Rats with bilateral lesions in midbrain reticular formation in comparison with sham-operated control rats showed a significant decrease in duration of orienting response (exploratory behavior) to a novel stimulus, although no differences were found in rate of habituation to the novel stimulus.

$$
\text { 3:05-3:20 C42 }
$$

Effect of Saccharin on Intake of Diluted Food by Hyperphagic and Normal Albino Rats. MOSHE J. LEVISON, WILLIAM B. VANCE, \& GABRIEL P. FROMMER, Indiana University -This experiment tested if the decreased intake by hypothalamic hyperphagic (VMH) animals of a diet diluted with a nonnutritive substance is due to its reduced palatability, by adding various concentrations of saccharin to the diet. Unoperated control Ss increased their daily intake significantly more than the VMH Ss, indicating that their decreased intake of diluted food is not due to a lack of palatability.

$$
\text { 3:20-3:35 C43 }
$$

Lateral Hypothalamic Aphagia and Anorexia Prolonged by Tube-Feeding. RICHARD E. KEESEY, TERRY L. POWLEY, \& LEE J. PERKO, University of Wisconsin-Rats sustaining lateral hypothalamic lesions were maintained at control weights by tube-feeding for 1 week postlesion. The aphagia and anorexia observed when tube-feeding was terminated was as prolonged as that seen in animals lesioned but not tube-fed. Active regulation to a lowered body weight set-point, rather than a process of neural recovery, best explains the duration of lateral hypothalamic aphagia and anorexia.

$$
\text { 3:40-3:55 C44 }
$$

Absence of Learned Poison Aversion in Recovered Lateral Hypothalamic Rats. SIDNEY R. ROTH, University of Washington, PHILIP TEITELBAUM, \& MYRNA SCHWARTZ, University of Pennsylvania-An attempt was made to train rats that had recovered from lateral hypothalamic lesions to avoid poisoned flavors. Although normals learned this problem easily, recovered laterals found it quite difficult. No sensory or specific affective deficits were noted. Recovered laterals maintained consistent flavor preferences. They also became severely anorexic following poisoning. An integrative deficit is indicated.

\section{Thursday Morning \\ Animal Conditioning}

$$
8: 45-8: 55 \mathrm{E} 1
$$

Acquisition of a Hurdle-Jump Response to Escape Cues Paired with Nonreward During Discrimination Learning. HELEN BOHMER DALY, SUNY at Oswego-Following discrimination-learning trials in two parallel runways, rats learned a hurdle-jump response to escape from the nonreinforced goalbox to a neutral box, indicating that an aversive motivational state exists during discrimination learning. These results are in contrast with Wagner's (1963), where no improvement across trials was obtained.

$$
\text { 8:55-9:15 E2 }
$$

Operant Behavioral Changes Occurring in a Low-Level Microwave Field. NANCY WILLIAMS KING, University of Missouri at Kansas City \& U.S. Veterans Administration, \& DON ROBERT JUSTESEN, VA Hospital \& K.U. Medical Center, Kansas City-Six male albino rats were exposed to intermittently presented intervals of closed-space, $2,450-\mathrm{MHz}$ UHF at power densities approximating 5,10 , or $15 \mathrm{~mW} / \mathrm{cm}^{2}$. Global operant licking rates, as recorded via photo-operandum, were found to be inversely related and highly reliably so to level of power density. Discriminative efficiency in a multiple schedule was not adversely affected, however, even at the highest power density; indeed, efficiency improved in three animals. The drop in global rate was characterized by a sudden cessation of responding within an hourly session; posturally, the animals appeared shortly thereafter to be in a flaccid, curariform narcosis. Attempts to use microwaves as $\mathrm{S}_{\mathrm{D}}$ were unsuccessful.

$$
\text { 9:20-9:35 E3 }
$$

Effects of the Concentration of Sucrose Reinforcement Upon Concurrent Operant Performances. DAVID L. ROLL, C. W. Post College (sponsored by Robert $W$. Schaeffer)-White rats responded on two concurrently available bars for sucrose solutions. Reinforcements were scheduled on concurrent, independently operating VI 2 min programs with a 5 -sec changeover delay. When the concentrations of the reinforcers differed, the proportion of responses and the proportion of time spent on a bar matched the proportion of solute delivered for responses on that bar.

$$
\text { 9:35-9:50 E4 }
$$

Positive Reinforcement as a Method for Inducing Rats to Ingest Intoxicating Quantitites of EtOH. R. J. SENTER, University of Cincinnati-This presentation 
consists of a motion picture narrated by the author. The movic demonstrates the use of operant positive reinforcement procedures to induce rats to drink intoxicating quantities of ethanol solution. The technique described engenders fairly high "voluntary" ingestion of EtOH, offering an alternative 10 force feeding or water deprivation.

\section{9:55-10:10 E5}

Effects of UCS Intensity and Schedule of Reinforcement on Extinction in Classical Nictitating Membrane Conditioning of the Albino Rabbit. JON P. WEIMER, DANIEL S. KIRSCHENBAUM, \& DALE W. LEONARD, University of Rochester-The effects of high $(80-\mathrm{V})$ and low (40-V) UCS intensities upon conditioning performance and resistance to extinction were investigated in two experiments for both continuous (CRF) and partial (PRF) reinforcement schedules. Although acquisition performance was a monotonic increasing function of UCS intensity, resistance to extinction was inversely related to UCS intensity for both CRF and PRF groups. This result is contrary to those obtained with PRF groups in instrumental conditioning. In classical conditioning, extinction appears to be a simple function of the amount of generalization decrement between acquisition and extinction phases. 10:10-10:25 E6

Rabbit Nictitating Membrane Response: Effects of Unpaired Presentations of the UCS on Conditioning and UCR Amplitude. JOHN W. MOORE, University of Massachusetts-Conditioning of the rabbit nictitating membrane response with electric shock as the UCS, and with an ITI of $100 \mathrm{sec}$, was impaired by the interpolation between trials of the UCS alone. In opposition to the conditioned diminution effect observed with humans, UCR amplitude to unpaired presentations of the UCS was smaller than on paired trials.

$$
\text { 10:30-10:35 E7 }
$$

(Read by title only)

The Effect of Interpolated US Presentations on Classical Conditioning of the Nictitating Membrane in Rabbits. LEWIS C. FISCHBEIN, JOYCE E. MONTEAU, \& DALE $W$. LEONARD, University of Rochester-The performance of two groups of rabbits that had US-alone presentations either $30 \mathrm{sec}$ (F.30) or $60 \mathrm{sec}$ (E60) following each reinforced (paired) trial was compared to a control group (C60) that received paired trials only at 60 -sec intervals. Group C60 outperformed either experimental group, which did not differ themselves. These data raise doubts concerning the consolidation hypothesis of Kettlewell and Papsdorf, since both $\mathrm{C} 60$ and E60 had equal consolidation periods. The results are favorable. however, to Rescorla's contingency view of conditioning. In addition, UR amplitudes on paired trials exceeded those on US-alone trials, contrary to results obtained with human $S$ s.

$$
\text { 10:35-10:40 E8 }
$$

(Read by title only)

A Computerized Hullian Conditioning Model. DALE W. LEONARD \& GUY C. PRENTICE, JR., University of Rochester-The Hullian habit-strength conditioning model was embodied in a FORTRAN computer program that searches out the parameters $\mathrm{D}, \mathrm{L}, \mathrm{O}$, initial habit strength, growth rate, $\mathbf{M}$, and yields the model's Likelihood Value with respect to any dichotomized (e.g., successes and errors) data set. The Hullian model, with only growth rate of habit strength as a free parameter for each $S$, compared favorably to a three-stage Markov model previously proposed by Theios and Brelsford (Psychological Review, 1966) when both models were fitted to the classical conditioning records of 101 rabbits.

\section{BREAK}

$$
\text { 10:55-11:15 E9 }
$$

Stimulus Selection in Animal Discrimination Behavior: Learning or Performance? DAVID R. THOMAS, University of Colorado-During testing for control of behavior by a particular stimulus dimension, the presence of other (dominant?) cues may mask control that is potentially present. Several experiments with pigeons and rats used as Ss demonstrate such masking and therefore indicate that "stimulus selection" sometimes occurs during testing rather than during training.

$$
\text { 11:15-11:30 E10 }
$$

Compound Stimulus Effects in Conditioned Suppression. EDWARD B. DOWNIE III, University of Houston, \& MARTIN M. SHAPIRO, Emory University-Eight groups of rats were trained to one stimulus and then a compound. The second stimulus element produced no suppression, nor did its removal affect suppression to the first stimulus element. Nevertheless, the compound stimulus produced suppression even after extinction to the first element.

$$
\text { 11:35-11:50 E11 }
$$

CER Acquisition: Shock Intensity, Shock Schedule, and Experimental Design Effects. RICHARD D. WILLIS, University of Florida (sponsored by G. Robert Grice)-Manipulated between Ss, partial reinforcement interacted with shock intensity in determining CER acquisition in 21 rats. There was no difference with a high shock, but there was a clear acquisition effect with a lower shock. When manipulated within $21 \mathrm{Ss}$, partial reinforcement effects occurred at both shock intensities (no interaction).

\section{1:50-12:05 E12}

The Intertrial Interval in Pavlovian Inhibitory Conditioning. R. G. WEISMAN, Queen's University at Kingston-Rats were trained to turn a wheel to avoid unsignaled shock. They then had Pavlovian differential conditioning, each group, with a different intertrial interval (ITI): $5,1.0,2.0$, and $5.0 \mathrm{~min}$. Test presentations on the avoidance baseline showed facilitation to CSt independent of ITI, but inhibition to CS- was an increasing function of ITI duration.

$$
\text { 12:05-12:15 E13 }
$$

Conditioning of Vocalization and Bar-Press in Monkeys. SHUN-ICHI YAMAGUCHI \& RONALD E. MYERS, Laboratory of Perinatal Physiology, NINDS, National Institutes of Health-Conditioning in monkeys to respond discriminatively for food by vocalizing, bar-pressing, or moving their heads up were compared. Discriminative conditioning of bar-press was very quickly established, whereas vocalization conditioning failed. Head-up conditioning was intermediate. The result was discussed in terms of the nature of control in monkey vocalization.

\section{Thursday Afternoon \\ Reinforcement}

$$
\text { 1:15-1:30 E14 }
$$

Temporal Effects of Reinforcement: A Negative "Frustration" Effect. J. E. R. STADDON, Duke University-In situations that show positive goal-gradients, reinforcement omission elevates subsequent responding (positive "frustration" effect). In an experiment showing a negative goal-gradient, reinforcement omission depressed subsequent responding (negative "frustration" effect). A simple nonmotivational explanation accounts for both these effects.

$$
\text { 1:30-1:45 E15 }
$$

Behavioral Contrast: The Effects of Response Suppression and Changes in Relative Reinforcement Frequency. AARON J. BROWNSTEIN, RONALD G. HUGHES, \& CRIGHTON NEWSOM, University of North Carolina at Greensboro-(1) Responding in one component of a mult FIFI schedule was suppressed by signaling reinforcement availability. Rate of responding in the unsignaled component increased. (2) Responding in one component of a mult VIVI was suppressed by blacking out the key except when pecking would be reinforced. Rate of responding in the normal component increased. (3) Using the black-out procedure, rate of responding in the normal component was sensitive to rate of reinforcement, in the component 
containing black-out. Both positive and negative con trast effects were found.

$$
\text { 1:50-2:00 E16 }
$$

Straight-Alley Performance as a Function of Number and Quality of the Reinforcer. CHRISTOPHER TAYLOR, Western Washington State College-Rats, at $80 \%$ body weight, ran for one pellet of $4.0 \mathrm{cal} / \mathrm{g}$ substance (Group 1), two pellets of $2.0 \mathrm{cal} / \mathrm{g}$ (Group 2), or four pellets of $1.0 \mathrm{cal} / \mathrm{g}$ (Group 3), with number of calories per trial being held constant for all groups. After 60 trials, conditions of Groups 1 an:d 3 were reversed for an additional 45 trials, while Group 2 remained the same.

$$
\text { 2:00-2:20 E17 }
$$

The Effects of Palatability Shifts Upon Subsequent Saccharin and Sucrose Intake. ALLAN B. ASHTON, DONALD GANDELMAN, \& JAY A. TROWILL, University of Massachusetts-Subjects(rats) were given a palatable saccharin or sucrose solution daily until intake stabilized. At that time, a second solution, either more or less palatable, was substituted for a period of 2 or 3 days. When Ss were subsequently returned to the original solution, intake was reliably increased over preshift levels. The results indicated differences due to solutions, deprivation conditions, and sex of Ss.

\section{2:25-2:40 E18}

Effect of Location in a Schedule of Partial Reward of Magnitude of Reward. E. J. CAPALDI, Purdue University-Partial reward consists in combining rewarded and nonrewarded trials. Reward magnitude may be large (or small) on all rewarded trials or large on some rewarded trials and small on others. Several findings emerging from two studies employing irregular schedules and long ITIs are reported. Generally speaking, large reward on some trials increased resistance to extinction while on other trials it decreased it.

$$
\text { 2:40-2:50 E19 }
$$

The Preference-for-Signaled-Shock Phenomenon: Reinforcing Effects of Signaling the Shock as a Function of Scrambling the Grid. JOHN J. FUREDY \& GERALD B. BIEDERMAN, University of Toronto-Inescapable, unavoidable 3-sec shocks were preceded by 5 -sec signals contingent on previously food-trained (FR 40) bar-pressing. Yoked-control Ss, receiving the same, but noncontingent, series of signals, indicated that the signal was reinforcing only if the shocks were delivered through an alternate, rather than scrambled, foot-grid system. Implications are discussed for previous reports of the preference-for-signaled-shock phenomenon.

\section{BREAK}

$$
\text { 3:10-3:30 E20 }
$$

Multiple $S \Delta$ Interruptions of Responding
Maintained by a Fixed-Interval Schedule of Electric-Shock Presentation. R. STRETCH, E. R. ORLOFF, \& G. J. GERBER, University of Western Ontario-Under FI schedules of food presentation, the characteristic pattern of responding survives repeated $S \Delta$ interruption (Dews, 1962). The present experiments demonstrate an identical phenomenon under circumstances in which the sole consequence of FI responding is the delivery of response-contingent shocks in squirrel monkeys. Implications for the concept of reinforcement are discussed.

$$
\text { 3:30-3:40 E21 }
$$

Rate and Accuracy of DRL Responding under Tandem and Brief-Stimulus Reinforcement Schedules. GEORGE BIGELOW, University of Minnesota (sponsored by Roy Pickens)-Rats worked for food on a second-order schedule requiring a fixed number of correctly spaced responses-FR (DRL $10 \mathrm{sec}$ ). In the brief-stimulus condition (conditioned reinforcement presented following correct DRL responses), the rate of response was higher, but accuracy was relatively unchanged as compared to the tandem condition.

\section{3:45-3:55 E22}

Schedule-Induced Aggression in Pigeons as a Function of Fixed-Ratio Value. DON R. CHEREK \& ROY PICKENS, University of Minnesota-Pigeons responding for food reinforcement on fixed-ratio schedules attacked live target birds during the postreinforcement pause. The intensity of attacks decreased gradually over successive experimental sessions, and, when no longer occurring, attacks could be re-elicited by changing the fixed-ratio schedule value.

$$
\text { 3:55-4:10 E23 }
$$

A Preliminary Analysis of the Dynamics of the Pecking Response in Pigeons. MARK RILLING, THOMAS J. KRAMER, \& HENRY R. ASKEW, Michigan State University-Data were collected using a transducer that was specifically designed to record the waveform of the pigeon's peck. Each response was reinforced. Photographs of the waveform of behavior on the transducer showed great variability. Responses were frequently asymmetrical with the rise time shorter than the fall time.

$$
\text { 4:15-4:30 E24 }
$$

Stimulus Control of Observing Behavior. RONALD E. SCHAUB, University of Calgary-In three observing-response experiments, pigeons were trained to peck a key on a mix FI1EXT food reinforcement schedule. By pecking at a second key, they could produce a brief intermittent cue indicating the component of the schedule in effect. After establishing reliable observing behavior, generalization tests were presented to determine the degree of stimulus control over the two responses.

\section{4:30 - 4:45 E25}

Effect of Fixed Ratio Size and Food Deprivation on Responding for Ethanol. RICHARD MEISCH \& TRAVIS THOMPSON, University of Minnesota -Oral e $\mathrm{thanol} r$ e i f force m c n $(0.25 \mathrm{ml} / \mathrm{reinforcement}$ at $8 \% \mathrm{~W} / \mathrm{V})$ maintained fixed ratios of $2,4,8,16,32,64$, and 128 in four rats at levels exceeding water control values. Food deprivation increased responding for ethanol but not for water.

$$
\text { 4:50-5:05 E26 }
$$

Effect of Morphine on Behavior Maintained by Four Simple Food-Reinforcement Schedules. TRAVIS THOMPSON, University of Minnesota-Rats, conditioned on three values of FR, VR, FI, and VI food-reinforcement schedules were administered $1.0,3.0$, and $6.0 \mathrm{mg} / \mathrm{kg}$ IP of morphine or saline. Overall response rate varied with schedule, schedule value, and morphine dose. The effect of morphine on overall rate varied with baseline saline rate generated by schedules, and the relative rate change also varied with the type of schedule. 5:05-5:15 E27

Observing Behavior During Chained Fixed-Ratio Schedules. ALICE R. JWAIDEH, Indiana University (sponsored by James A. Dinsmoor)-Reinforcing effects of stimuli in chained fixed-ratio schedules of reinforcement were investigated. Pigeons pecked an observing key to produce, on the food key, a series of stimuli that changed after every nth response. Stimuli associated with later chain components were stronger reinforcers than stimuli associated with early components.

\section{Friday Morning, Motivation}

$$
\text { 9:00-9:15 E28 }
$$

Developmental Changes in Chick Approach Preferences for Social and Food Stimuli. GLORIA J. FISCHER, Washington State University-Four- through 10-day-old chicks were given choice preference trials in a T-maze to food or other chicks. Prior food and social deprivation were varied. Both response choice and latencies revealed a high and persistent interest in chicks' overall age groups tested. Thus, diminished interest in social stimuli with age may be excluded as a factor affecting the upper limit of the critical period in imprinting

$$
\text { 9:15-9:25 E29 }
$$

Aggressive Displays During Visual Reinforcement of Siamese Fighting Fish. RONALD BAENNINGER, Temple University-Siamese fighting fish were observed during $2-h$ sessions of responding for visual reinforcement. Aggressive display measures to the mirror were recorded, as well as operant responses that turned on the mirror. There was a lack of correspondence between operant and elicited responses. 
Such correspondence has usually been assumed.

$$
\text { 9:30-9:45 E30 }
$$

The Effects of Wheel-Running Behavior on Blood Glucose and Serum-Free Fatty Acid in Rats. MELVIN P. ENNS \& N. R. REMLEY, Texas Christian University (sponsored by Stephen Winokur)-Blood sugar and serum FFA were analyzed in food-deprived and nondeprived rats following wheel running. Increased activity altered both physiological measures in the direction of nondeprived Ss. The effect was a function of per cent weight loss and the amount of time spent in the wheel.

$$
\text { 9:45-10:00 E31 }
$$

Disappearance of Humoral Satiety Factor During a Fast. JOHN D. DAVIS \& CONSTANCE CAMPBELL, University of Illinois, Chicago Circle-Previous research has demonstrated the existence of a humoral satiaty factor in food-satiated rats. Such a factor should disappear during a fast. This assumption was confirmed by blood-transfusion studies showing the factor present in nondeprived rats and absent in rats deprived of food for $4-5 \mathrm{~h}$.

$$
\text { 10:05-10:20 E32 }
$$

Evidence for Learning of Sodium Hunger. MONCRIEFF H. SMITH, University of Washington-Although a theory that attributes sodium hunger to an alteration to the response to the taste of sodium per se seems by now to be fairly well established, there are indications that a feedback mechanism operates as well. Three experiments are to be reported that show the role of feedback and help reconcile some discrepancies in the literature.

\section{0:20-10:30 E33}

Slow Extinction of a Change in Preference for Flavored Water. SAMUEL $H$. REVUSKY \& MARTIN PSCHIRRER, Northern Illinois University-In an experiment reported earlier, month-old rats were permitted to drink one flavor of water while 2 days thirsty, and a second flavor while nearly satiated for water. In a 2 -h preference test, they preferred the flavor received while thirsty. We now can report that this effect frequently does not extinguish over 7 days of continual access to both flavors.

\section{BREAK}

$$
\text { 10:50-11:10 E34 }
$$

Failure to Extinguish Conditioned Thirst: Avoidance, Preparedness, or Functional Autonomy? MARTIN SELIGMAN, CHARLES IVES, HAROLD AMES, \& SUE MINEKA, Cornell University When a compound CS of a white box and a mild water deprivation are paired with strong thirst caused by saline injections, rats strongly increase drinking during the CS.
Such conditioned thirst shows no extinction across $2,475 \mathrm{~min}$ of unreinforced exposure to the CS. Evidence is presented that suggests that rats are "prepared" to associated mild thirst with strong thirst, and that this nonarbitrary association may not obey the "law of extinction" as associations between arbitrary stimuli do.

$$
\text { 11:10-11:25 E35 }
$$

Drinking in Response to Volume Depletion is Accompanied by Osmotic Pressure Increase. C. ROBERT ALMLI, Michigan State University (sponsored by L. I. O'Kelly)-Water intakes (I) and blood plasma conditions of rats were measured following (a) injection of hypertonic saline, (b) hemorrhage, and (c) injection + hemorrhage. Water intakes were additive, i.e., la $+\mathrm{Ib}=$ Ic. Significant osmotic pressure elevations were obtained under all conditions, even following hemorrhage, which was previously thought to be free of osmotic pressure changes.

\section{1:30-11:45 E36}

Ad Libitum Levels of Plasma Osmotic Pressure as a "Set Point" for the Satiation of Thirst. C. T. BENNETT \& G. I. HATTON, Michigan State University-Water-deprived rats were permitted to drink to a satiety criterion. By the time they stopped drinking, enough water had been absorbed to reduce plasma osmotic pressure to ad libitum levels. These data are consistent with a cellular rehydration theory of satiety.

$$
\text { 11:50-11:55 E37 }
$$

(Read by title only)

Executive Polydipsia. J. D. KEEHN, York University \& Addiction Research Foundation, Toronto-Detailed observations were made of the eating and drinking behavior of a pair of hooded rats under a VI 1-min schedule of food reinforcement after one of them (executive) had been trained alone to bar-press. Reinforcements could be consumed by either rat. The executive nearly always drank after eating; the other (control) never did. Eventually the control acquired the bar-press response. When it was then run alone, it, too, came to drink after eating. It is argued that schedule-induced polydipsia is not simply postprandial drinking; unprogrammed effects of reinforcement and "emotional" factors are implicated instead.

\section{Friday Afternoon}

\section{Animal Behavior (General)}

$$
\text { 1:00-1:20 E38 }
$$

Making Decisions Based on Two-Stimulus Dimensions. ERIC G. HEINEMANN \& SHEILA CHASE, Brooklyn College of CUNY-Pigeons were taught a conditional discrimination involving compound stimuli (light and sound). Whether or not the light component predicted reinforcement depended upon the value of the sound component, and vice versa. Generalization curves obtained after training can be accounted for by statistical decision theory and a concept of attention.

$$
\text { 1:20-1:35 E39 }
$$

Image-Induced Aggressive Display: Reinforcement in the Paradise Fish. KENNETH B. MELVIN, University of Alabama, \& JOHN E. ANSON, Stephen F. Austin State University-A mirror presentation and the ensuing species-specific aggressive display served as a reinforcer for paradise fish (Macropodus opercularis). Learning and extinction curves we re shown with this type of reinforcement; however, noncontingent mirror presentations did not maintain operant performance. A declining trend in response rate with repeated image/display reinforcements reflected some habituation of the display.

$$
\text { 1:40-1:50 E40 }
$$

Mirror-Image Stimulation and Self-Recognition in Primates. GORDON G. GALLUP, JR., \& MICHAEL K. MCCLURE, Tulane University-Chimpanzees and a variety of monkeys were given prolonged individual exposure to mirrors. Through time-sampling procedures, a number of behavioral changes to the mirror image were noted. In general, there was a decrease in social responses and an increase in self-directed behaviors. By anesthetizing animals and implementing temporary appearance changes, direct evidence for self-recognition in the mirror was obtained.

$$
\text { 1:50-2:05 E41 }
$$

Hormone and Brain Control of Territoriality in the Gerbil-DELBERT D. THIESSEN, University of Texas-Mongolian gerbils (Meriones unguiculatus) mark objects in their environment with a ventral sebaceous scent gland. The response is androgen-dependent and can be evoked by androgen implants into the brain. Small amounts of Actinomycin D, implanted along with the hormone, blocks the induction of marking.

$$
\text { 2:10-2:20 E42 }
$$

Food Imprinting in Domestic Chicks as a Function of Social Contact and Number of Companions. MERLE E. MEYER \& LAWRENCE H. FRANK, Western Washington State College--Three-day-old cockerel chicks were trained to peck a green stimulus for food in preference over a blue stimulus within a social, visual, or isolated condition, or within a $1-, 2-, 3-$, or 4-S group. The chicks were tested on 4 subsequent nonreinforced days to ascertain the generality of "food imprinting." On the initial reinforced day, the chicks discriminated between the two stimuli. The social birds pecked more than the visual group and the visual more than the isolated, and the larger the group number, the higher 
the mean rate. Over the nonreinforced days, all groups showed a rapid decline in the frequency of responses. The data were interpreted as extinction rather than as "food imprinting."

$$
\text { 2:20-2:35 E43 }
$$

Hyperphagia and Polydipsia in Socially Isolated Rhesus Monkeys. WILLIAM F. CAUL \& ROBERT E. MILLER, University of Pitsburgh-Three rhesus monkeys that had been isolated from all social contact during their first year of life were found to exhibit persistent overeating and overdrinking during adulthood. The isolates ingest approximately twice as much fluid and food as do normally reared control animals.

$$
\begin{gathered}
2: 40-2: 45 \text { E44 } \\
\text { (Read by title only) }
\end{gathered}
$$

Social Behavior of Toads. CAROL BOICE, University of Missouri, Columbia (sponsored by Melvin H. Marx)--Six groups of six toads (Bufo americanus) were observed for 16 weeks during competitive and noncompetitive feeding. Ss were housed in terraria and fed three times per week. Although the feeding-order hierarchies in both situations were statistically stable, agreement between competitive and noncompetitive rankings was only moderate. Social dominance orders are evidently situation specific in this species. Aggressive interactions, including striking with the tongue, confrontations, and approaches, remained at a high level throughout observation. Aggression was most often observed between animals competing for food. The most aggressive animals tended to occupy middle ranks in the feeding orders.

\section{BREAK}

\section{3:00-3:10 E45}

Eye Movements as an Operant in the Cat: Preliminary Observations. M. A. BERKLEY \& JUDITH E. TUNKL, Florida State University (sponsored by Charles Spielberger)-Electrical potentials due to eye movements were recorded through silver-silver chloride electrodes implanted at the outer canthi of both eyes. Electro-oculograms exceeding a predetermined level were reinforced with food. To minimize head movements, the animals were required to depress a nose key while performaning the eye-movement response.

$$
\text { 3:10-3:25 E46 }
$$

Schedule Control of the Vocal Behavior of Cebus Monkeys: A Progress Report. J. D. LEANDER, M. A. MILAN, K. B. HEATON, K. B. JASPER, \& A. S. MORRIS, University of Florida (sponsored by Henry $S$. Pennypacker)-An examination of the effects of various reinforcement schedules upon the vocal behavior of Cebus monkeys is being conducted. The present report deals with basic instrumentation and techniques for obtaining control of this class of behaviors by response-contingent reinforcement. Data from three $\mathrm{Ss}$ on various FR schedules will also be presented. 3:30-3:40 E47

Adrenal Response of Infant Rhesus Monkeys to an Unfamiliar Environment With and Without a Social Surrogate Present. SUZANNE D. HILL \& SHIRLEY A. McCORMACK, Delta Regional Primate Research Center-Infants were placed in a distinctive visual environment with a social surrogate at Day 1. Blood samples were obtained from each animal at monthly intervals for 6 months: (1) unfamiliar environment-familiar surrogate; (2) unfamiliar environment-no surrogate; (3) familiar environment-familiar surrogate. Developmental changes in adrenal response were noted.

$$
\text { 3:40-3:50 E48 }
$$

Sleep of Two Inbred Rat Strains. W. B. WEBB \& J. K. FRIEDMANN, University of Florida (paper read by $J$. K. Friedmann)-Cortical and hippocampal EEG recordings were obtained for 24-h periods from four rats each from two inbred strains (ACI/Mai and F344/f Mai). Records were scored for sleep, paradoxical sleep, and waking. Analyses were made on length and number of cycles, diurnal periodicity, and totals for the three variables.

$$
\text { 3:55-4:10 E49 }
$$

Habituation: Characteristics of the Process Tested in Worms. STANLEY C. RATNER, Michigan State University-Twenty earthworms, L. terrestris, were tested for habituation to two classes of stimuli, vibratory and photic. Differences between habituation to these stimuli are examined and correlations between the two types of habituation sessions are determined. These results relate to questions about the stability of habituation and a theory of effects of type of elicitation on habituation.

$$
\text { 4:15-4:20 E50 }
$$

(Read by title only)

Incentive Reduction Effects in a Runway as Function of Number of Preshift Training Trials and Pretraining Rewarded Goalbox Placements. ALVIN J. NORTH, University of Texas Southwestern Medical School at Dallas-In Experiment 1, Ss had 108 or 18 large-reward trials followed by 63 small-reward trials. Run and goal speeds of 108-trial Ss declined below those of 18-trial Ss, but subsequently recovered further. In Experiment 2, Ss had 90 or 0 large-reward pretraining-rewarded goalbox placements, followed by 30 large- and 63 small-reward trials. Control Ss had no placements and $s \mathrm{mall}$ reward throughout. Both experimental groups exhibited a depression effect, but did not differ in its extent. In Experiment 3, which substantially replicated Experiment 2, similar findings were obtained.

$$
\text { 4:20-4:25 E51 }
$$

(Read by title only)

Competition Under Two Schedules of Reinforcement. CHARLES D. CORMAN \& ROBERT S. RUSKIN, West Virginia University -Four male rats were tested alone and in pairs in a "nose poke" apparatus, Paired sessions were videotaped to permit tabulation of: S's responses, transitions in responding, time adjacent to hole, locomotor activity, and social interactions. "Round-robin" testing under CRF produced linear hieraschy for responses/session. Each S's response rate was inversely related to the hierarchical position of his competitor. Transitions and social interactions were inversely related to differences in response rates. The "highest" $\mathrm{S}$ within pairings initiated the most social interactions. A shift to FR10 increased response rate differences and decreased transitions and social interactions.

\section{Saturday Morning \\ Animal Sensory Functions}

$$
\text { 9:00-9:10 E52 }
$$

Spectral Sensitivity of the Pigeon. VIRGIL GRAF, Dartmouth College-A method was developed for using flicker photometry in determining photopic spectral sensitivity in the pigeon. The overall spectral curves obtained from two animals were found to be in substantial agreement with previously published data. However, the standard error of measurement of the overall curve for the two pigeons was .035 of a log unit. The standard error of measurement for the spectral curves of each animal was .050 of a log unit.

$$
\text { 9:10-9:25 E53 }
$$

Spectral Sensitivity of Single Units in the Diencephalon of Pigeon. A. M. GRANDA \& S. YAZULLA, JR., University of Delaware-Units isolated in the nucleus rotundus displayed an increased discharge to light onset; a few discharged to both onset and offset of light. Several units were actively inhibited by light. Spectral sensitivity curves were similar to the absorption spectrum for rhodopsin with $\lambda \max$ near $500 \mathrm{~nm}$.

$$
\text { 9:30-9:45 E54 }
$$

Evaluation of the Use of Intracranial Stimulation in Animal Psychophysics. ROBERT L. YOLTON \& GERALD $H$. JACOBS, UC, Santa Barbara-Many of the difficulties inherent in animal psychophysics are associated with the nature of the reinforcement technique employed. The efficiency of using brain stimulation as a reinforcer was evaluated by 
training ground squirrels to perform difficult visual discriminations for either food reward or brain stimulation.

$$
\text { 9:45-9:55 E55 }
$$

A Comparison of Horizontal and Vertical Optokinetic Nystagmus from Parrots, Cats, and Men. WILlIAM E. COLLINS, Civil Aeromedical Institute, \& NANCY RICE, FAA, Oklahoma City-Optokinetic ocular responses differ among parrots, cats, and men. Data are compared in terms of adaptation, continuation of primary nystagmus following cessation of stimulation, secondary nystagmus, and directional differences. The latter is prominent only with respect to vertical nystagmus and arousal is a potent factor in preventing adaptation.

10:00-10:05 E56

(Read by title only)

Determinants of the Rebound Effect in the Optokinetic Response of the Guinea Pig. WILLIAM N. HAYES \& LEONARD C. IRELAND, SUNY at Buffalo--.Reversal of the optokinetic drum after a lengthy prereversal exposure gives rise to a large increase in OKR frequency. This sudden increase has been called a rebound effect. Three experiments were done to shed some light on the mechanism underlying this effect. It was found that: (a) insertion of a delay between prereversal and reversal decreases the rebound effect; (b) longer prereversal exposures yield larger rebound effects; and (c) the rebound effect could only be obtained with appropriate visual stimulation present. These results are consistent with the idea that there is a build-up of inhibition that is removed by reversal.

\section{0:05-10:10 E57}

(Read by title only)

The Effects of Ionizing Radiation on the Visual System of the Noctuid Moth, Heliothis zea. KENNETH L. SCHAFER, JR., \& JAMES C. SMITH, Florida State University-Flight activity and electrophysiological responses were obtained from dark-adapted moths when stimulated with gamma, beta, or $\mathrm{X}$-irradiation. Interactions between light stimulation and ionizing radiation were also investigated. When dark-adapted moths were stimulated with brief flashes of diffuse white light, the electroretinogram produced by the white light could be reduced in amplitude by presenting a background stimulus of ionizing radiation. The magnitude of the effect was dependent upon dose rate, flash intensity, and flash duration. Dark-adaptation functions plotted for the b-wave of the electroretinogram utilizing light and beta source stimuli suggested that the action of the ionizing radiation was on the photochemical processes of the reticular cells. Dark-adaptation to the beta radiation was unaffected by the pigment migration mechanism, while the function obtained using white light showed both photochemical and mechanical processes.

\section{BREAK}

$$
\text { 10:25-10:40 E58 }
$$

Critical Bands in Monkeys. GEORGE GOUREVITCH, Hunter College of CUNY, \& HAYDEN W. MATHEWS, Princeton University-Absolute and masked thresholds were measured in two monkeys (Macaque nemestrina). At two frequencies, masked thresholds were obtained under different bandwidths of noise; at three other frequencies, the masker was a two-tone complex, one on each side of the signal, and masked thresholds were measured for different frequency separations between the two tones. From these measurements, critical bands were determined for five frequencies ranging from .5 to $16 \mathrm{kHz}$.

\section{0:40-10:55 E59}

Characteristics of Mammalian Hearing BRUCE MASTERTON \& HENRY HEFFNER, Florida State University-The distributions of five descriptive parameters of hearing, along with some of their morphological correlates, will be reviewed and up-dated. The most likely course of evolution of human hearing will then be traced through comparison of those animals that are the closest approximations to mammals in mankind's ancestral lineage.

$$
\text { 11:00-11:15 E60 }
$$

A Technique for Determining Loudness Difference Thresholds in the Turtle. W. C. PATTERSON, F. C. EVERING, \& CATHERINE T. HOWELL, University of Vermont-Preliminary data indicate success with a behavioral method for measuring loudness difference thresholds in a Pseudemys scripta elegans. The turtle avoids shock by head withdrawal when a pulsing background tone changes in intensity. This procedure is an automated extension of a technique developed by Patterson (1966) for determining absolute thresholds. 11:15-11:25 E61

Localization of Pure Tones. J. $\mathrm{H}$. CASSEDAY, Indiana University, Bloomington (sponsored by William D. Neff)Eight cats were trained to localize pure tones in space. The tones were at octave intervals from $250 \mathrm{~Hz}$ to $8 \mathrm{kHz}$. Threshold data of the minimal detectable angle indicates that the cat's performance in localizing is poorest at $4 \mathrm{kHz}$, and improves at either higher or lower frequencies.

$$
\text { 11:30-11:45 E62 }
$$

The Psychophysics of Chemical Prey Recognition in Naive Snakes. GORDON M. BURGHARDT, CHERYL S. HUFF, \& THOMAS A. FIEDLER, University of Tennessee-Newborn garter snakes
(Thamnophis) without prior feeding experience were repeatedly tested with various concentrations of prey-attack-eliciting chemicals extracted from species-characteristic prey. Concentrations as low as .001 of the raw extract led to increased responding over distilled water. Considerable individual differences were uncovered, along with hysteresis, habituation, and other effects.

\section{Thursday Morning}

\section{Avoidance Learning}

$$
\text { 9:15-9:30 F1 }
$$

Interference Effects of Escapable Shocks upon the Subsequent Acquisition of Escape-Avoidance Responding. PERRIN S. COHEN, Florida State University (sponsored by Richard L. Solomon)-Dogs, restrained in a harness and exposed to an escape procedure that selectively reinforced long response latencies and IRTs, subsequently failed to acquire an escape/avoidance response in a shuttlebox within 14 trials. Such interference, sometimes interpreted as "learned helplessness," need not be due to a history of noncontingent shocks.

$$
\text { 9:30-9:40 F2 }
$$

Frustration and Shock-Escape Behavior in the Rat. JOSEPH V. LAMBERT \& L. H. HAMMOND, Temple University (paper read by L. H. Hammond)-The Amselian frustration effect (FE) was studied in a double runway with shock escape instead of food reward. Rats ran slower after "frustration" than after "relief." In a second experiment, this "reversed" FE did not appear until the 20th trial, when running to the first goalbox was partially reinforced from the beginning.

\section{9:45-10:00 F3}

Failure to Escape Electric Shock: Incompatible Motor Responses or Learned Helplessness? STEVEN F. MAIER, University of Illinois (sponsored by Lloyd G. Humphreys)-One group of dogs, the escape group, was trained to escape shock in a Pavlov harness by inhibiting movements elicited by shock. A yoked group received shocks yoked to the escape group. A control group received no shocks. The escape group subsequently learned to escape in a shuttlebox more slowly than did the control group, but eventually learned. Half of the yoked dogs never learned. The relevance of these results for a theory of learned helplessness is discussed.

\section{0:00-10:15 F4}

Escape Compared with Avoidance Conditioning in Neonatal Dogs. W. C. STANLEY, J. E. BARRETT, \& W. E. BACON, National Institute of Mental Health-Escape-trained beagles $(\mathrm{N}=8)$ were reliably superior in performance during 
training, but did not differ from avoidance-trained Ss $(\mathrm{N}=8)$ during extinction. Analysis of individual performance indicated that the general form of conditioning and extinction in dogs less than 11 days old is on the same continuum as adult learning.

$$
\begin{aligned}
& \text { 10:15-10:20 F5 } \\
& \text { (Read by title only) }
\end{aligned}
$$

Conditions Affecting the Intersession Facilitation of Shuttlebox Avoidance Responding in Guinea Pigs. C. D. WEBSTER, Addiction Kesearch Foundation-Although guinea pigs typically fail to perform a shuttlebox avoidance response during an initial training session, they show marked avoidance facilitation when tested $48 \mathrm{~h}$ later (Webster \& Rabedeau, 1964). The present series of experiments sought to isolate the necessary and sufficient conditions for the occurrence of this intersession facilitation effect (ISFE). Intersession (ISI) facilitation of avoidance behavior occurred only if the guinea pigs had first learned to escape from signaled shock (i.e., during training), if the same signal was employed during training and testing, if the signal used in the escape training session terminated shortly after the escape response, and if the guinea pigs were removed from the shuttlebox for a relatively long time between sessions. Further study showed that the effectiveness of the removal procedure was entirely due to the fact that it prevented the guinea pigs from responding during the ISI: guinea pigs confined by a partition to one compar tment during the ISI avoided at the same level as Ss that spent the ISI in their home cages.

\section{BREAK}

\section{0:35-10:50 F6}

Effect of a Preaversive Stimulus on Avoidance Decline. A. E. ROBERTS \& H. M. B. HURWITZ, University of Tennessee-Nine rat Ss trained under an FOA schedule involving three shock intensities were exposed to a conditioned suppression procedure. During the periods in which CS was superimposed on responding, the FOA schedule was not in effect (time-out). Responding decreased during CS when CS was followed by shock (US). When US was omitted, responding increased during CS but was lower than non-CS rates.

\section{0:50-11:05 F7}

The Inverse Relationship Between Shock Intensity and Shuttlebox Avoidance Learning: A Reinforcement Explanation Based on Fear. WALLACE R. M c A LLISTER, DOROTHY E. MCALLISTER, Northern Illinois University, \& W. KEITH DOUGLASS, Syracuse University-Following 65 shuttlebox avoidance training trials with either 0.3 - or 1.6-mA shock intensity, rats were allowed, in the absence of both shock and the CS, to jump from one compartment of the shuttlebox to an adjacent safe box. The $1.6-\mathrm{mA}$ group made significantly fewer avoidance responses than the $0.3-\mathrm{mA}$ group, but jumped into the safe box with significantly shorter latencies. A reinforcement interpretation based on fear can account for the findings.

$$
11: 10-11: 25 \mathrm{~F} 8
$$

Retention of Passive Avoidance Learning. PAULINE JIRIK SINGH \& F. ROBERT BRUSH, University of Oregon Medical School (paper read by F. Robert Brush)-The U-shaped retention function that characterizes relearning and extinction of active avoidance responding also describes recovery of bar-pressing for food following passive avoidance training. Controls that were shocked when bar-pressing was precluded showed little suppression and no effect of the retention interval. Implication of these results for memory and motivation are discussed.

$$
\text { 11:30-11:35 F9 }
$$$$
\text { (Read by title only) }
$$

Discriminated Avoidance Learning in Salamanders. JAMES N. SHAFER \& PAUL W. BRUNK, West Virginia University-Salamanders (Desmoquathus quadramaculatus), tested in a circular runway with an electric shock US and a vibratory CS, rapidly acquired an avoidance swimming response that reliably decreased during extinction. Control animals tested with unpaired CS-US presentations showed neither an acquisition nor an extinction effect. There was an increase in the number of avoidance responses in each daily session followed by a lower level of responding the following day. Improvement in performance as measured by response latency was also observed. Ss have been maintained under laboratory conditions for as long as 18 months with only accidental fatalities.

$$
\text { 11:35-11:40 F10 }
$$

(Read by title only)

Determinants of Transituational Desensitization to an Aversive Stimulus. WILLIAM TERRIS \& ROBERT MALESKE, De Paul University-Using a modified yoked-control design, 40 albino rats received: (1) training to press a bar that produced food and gradually increasing intermittent shock punishment, (2) food-shock pairings independent of a bar-press response, (3) unpaired food and shock independent of a response, or (4) food without shock independent of a response. All Ss were subsequently tested in a novel conflict situation. While all three groups having prior experience with the shock during training subsequently showed significantly greater resistance to shock punishment in the conflict testing situation, the difference among the prior-shock groups was not significant.

\section{Frida! Morning}

Psychopharmacology

$$
\text { 9:30-9:40 F20 }
$$

Effects of TCAP on Spatial Discrimination Learning in the Rat. EDWARD $M$. GUROWITZ \& ROBERT NOVICKI, C. W. Post College-Chronic TCAP administration has been reported to facilitate learning. Rats $(\mathrm{N}=14)$ were given TCAP $(45 \mathrm{mg} / \mathrm{kg})$ or saline for 30 days and run on a two-bar discrete-trial discrimination. Ss did not differ in acquisition, but drug animals learned reversal more readily $(\mathrm{p}<.05)$. A complex task may be needed to obtain the facilitation effect.

$$
\text { 9:40-9:55 F21 }
$$

Extinction and Spontaneous Recovery Under Magnesium Pemoline and Scopolamine. P. M. ADAMS, F. T. CRAWFORD, \& G. R. LAWRENCE, Florida State University-Following training on an FI schedule, rats were given either continuous extinction or a test for spontaneous recovery. Ss were given either magnesium pemoline $(20 \mathrm{mg} / \mathrm{kg})$, scopolamine hydrobromide $(10 \mu \mathrm{g} / \mathrm{kg})$, or served as no-drug controls. Magnesium pemoline Ss responded at a significantly greater rate than did scopolamine or control Ss in normal extinction and spontaneous recovery. Scopolamine $\mathrm{S} s$ were significantly lower than magnesium pemoline and control Ss in normal extinction, and failed to show any spontaneous recovery.

10:00-10:15 F22

Development of Strychnine Sensitivity in Chick Embryos. ROBERT PROVINE, Washington University (sponsored by T. T. Sandel)-Behavioral observations and microelectrode recordings from spinal cord of chick embryos reveal increases in regularity and frequency of strychnine-induced convulsive discharges as a function of age. Results suggest changing role for strychnine-sensitive postsynaptic inhibition during maturation. The change in strychnine response occurs during the developmental period in which the embryo begins coordinated behavior associated with hatching.

$$
\text { 10:15-10:25 F23 }
$$

Dosage Effects of Methy:phenidate on Learning of Children. ROBERT $L$. SPRAGUE, University of Illinois, JOHN S. WERRY, Institute for Juvenile Research, WARREN E. GREENWOLD, \& HELEN JONES, University of Illinois-Dosages of me thylphenidate $(0.10 \mathrm{mg} / \mathrm{kg}, 0.20 \mathrm{mg} / \mathrm{kg}$, $0.30 \mathrm{mg} / \mathrm{kg}, 0.40 \mathrm{mg} / \mathrm{kg}$, placebo, and no drug) were given to each of 16 emotionally 
disturbed children. Each $S$ received each dosage. Chasroom observations and iccuritcy and latency measures on a recognition task with threc levels of stimulus complexity were taken. A significant Dosage by Stimulus Complexity interaction on accuracy was obtained.

\section{BREAK}

\section{0:45 10:55 F 24}

Performance of Rats on Random Interval Schedules of Reinforcement as a Function of Amount of Combusted Cannabis Inhaled. JOAN G. BORRISON, MICHAEL L. COMMONS, \& JOHN A. MOLINO, Columbia ! Iniversity (sponsored by Clifford T. Morgan)-Dose-effect curves for the combustion products of cannabis were determined in three hooded rats. They obtained water on a random-interval schedule with $\mathrm{T}=10 \mathrm{sec}, \mathrm{P}=.4$. Latency to the first bar press increased and rate of responding decreased as either amount of cannabis or duration of inhalation increased. 10:55-11:10 F25

Effects of Lysergic Acid Diethylamide (LSD-25) on Retention Performance of Weanlings. EDWARD T. UYENO, Stanford Research Institute-The effects of lysergic acid diethylamide on rat pups at the age of 18 days, were evaluated with the Lashley-II maze. The time of peak effect of the hallucinogen was 5 min after the injection. The dose-response experiment conducted at the time of peak effect showed that the disrupting effect on previously learned maze performance was a function of dose.

$$
\text { 11:15-11:30 F26 }
$$

Overtraining-Induced Transfer of Drug-Dissociated Learning in Rhesus Monkeys. DAVID K. BLISS, SUNY at Binghamton (sponsored by Peter $J$. Donovick)-Rhesus monkeys trained on four concurrent color discrimination problems while drugged (pentobarbital) or normal were tested for transfer in the opposite state after solving each problem. In early tests, there was no transfer. Later, overtrained problems (those first solved) showed almost perfect transfer, while recently solved problems did not transfer.

\section{1:30-11:45 F27}

Effects of US Magnitude (Drug Dose) on Conditioning of Drug Response. JOHN A. DOUGHERTY \& ROY PICKENS, University of Minnesota-A conditioned drug response was established in rats with intravenous methamphetamine injection (US) paired with stimulus-light illumination (CS). Effects of two drug doses as US were determined: $0.5 \mathrm{mg} / \mathrm{kg}$, which elicited a large activity increase, and $4.0 \mathrm{mg} / \mathrm{kg}$, which initially suppressed activity. Activity CR was found to be US dose dependent. 